\title{
Otto der Grosse und das Römische Reich. Kaisertum von
} der Antike zum Mittelalter

Ausstellungskatalog, hg. von Matthias Puhle und Gabriele Köster, Regensburg : Steiner, 744 p, 39,95€

\section{Charles Mériaux}

\section{OpenEdition}

\section{Journals}

Édition électronique

URL : http://journals.openedition.org/ifha/8110

DOI : 10.4000/ifha.8110

ISSN : 2198-8943

\section{Éditeur}

IFRA - Institut franco-allemand (sciences historiques et sociales)

\section{Référence électronique}

Charles Mériaux, "Otto der Grosse und das Römische Reich. Kaisertum von der Antike zum Mittelalter », Revue de I'IFHA [En ligne], Date de recension, mis en ligne le 14 avril 2015, consulté le 22 septembre 2020. URL : http://journals.openedition.org/ifha/8110 ; DOI : https://doi.org/10.4000/ifha.8110

Ce document a été généré automatiquement le 22 septembre 2020

(CIFHA 


\title{
Otto der Grosse und das Römische Reich. Kaisertum von der Antike zum Mittelalter
}

\author{
Ausstellungskatalog, hg. von Matthias Puhle und Gabriele Köster, \\ Regensburg : Steiner, 744 p, 39,95€
}

\section{Charles Mériaux}

Le Kulturhistorisches Museum de Magdebourg a saisi le prétexte du 1100e anniversaire de la naissance, le 23 novembre 912, d'Otton Ier, roi de Germanie, roi d'Italie, empereur, pour présenter l'exposition dont est issu le présent catalogue. Bien que le premier empereur saxon se trouve placé au cœur de l'événement, il n'était pas possible d'en faire l'unique sujet de cette manifestation. On se souvient en effet que le musée de Magdebourg avait présenté en 2001 une exposition intitulée Otto der Grosse, Magdeburg und Europa dont la catalogue en deux volumes reste aujourd'hui une excellent introduction au règne et à la personne du premier souverain de la dynastie ottonienne. C'est en fait le sous-titre - Kaisertum von der Antike zum Mittelalter - qui donne la meilleure idée du contenu du catalogue. Otton Ier est le point d'aboutissement d'une histoire des différentes formes prises par l'Empire en Occident et qui constituent chacune une section du catalogue : les origines augustéennes (I), Constantin et l'Empire chrétien au IVe siècle (II), les transformations de l'héritage antique à Byzance (III), la renaissance impériale carolingienne (IV) et, enfin, la seconde rénovation ottonienne du Xe siècle $(\mathrm{V})$. Chacune de ces parties est introduite par une carte récapitulative ainsi que deux ou trois exposés synthétiques confiés aux meilleurs spécialistes, suivis par le catalogue des objets exposés, prêtés par des bibliothèques et musées de toute l'Europe. Sarcophages, bustes, statues, bronzes, ivoires, étoffes, reliquaires, bijoux, armes, inscriptions, mosaïques, monnaies, manuscrits et diplômes, sceaux et bulles, plans, cartes permettent ainsi de suivre en images la permanence et les transformations de l'idée d'Empire pendant un millénaire. Comme toujours, le lecteur français referme le livre avec admiration devant l'efficacité avec laquelle nos voisins allemands mobilisent 
conservateurs, spécialistes et mécènes pour donner à voir au grand public un pan essentiel des origines antiques et médiévales de l'Europe occidentale.

INDEX

Index chronologique : Moyen Âge

Thèmes : Histoire de la culture

\section{AUTEUR}

\section{CHARLES MÉRIAUX}

Université Charles-de-Gaulle Lille 3 